Indonesian Journal for Social Responsibility (IJSR) Vol. 3, No. 02, (2021), hal. 75-82

\title{
PENINGKATAN KUALITAS SUMBER DAYA MANUSIA MELALUI PELATIHAN PERANAN HUMAS BAGI ANGGOTA POLRESTA TANGERANG
}

\author{
Heriyanti ${ }^{*}$, Ummanah, Resman Maharul Tambunan \\ Fakultas IImu Komunikasi, Universitas Esa Unggul, Indonesia \\ E-mail: heriyanti@esaunggul.ac.id*,ummanah@esaunggul.ac.id, Resman.muharul@esaunggul.ac.id \\ Received: April 30, 2021 / Revised: July 21, 2021 | Accepted: August 6, 2021 \\ DOI: https://doi.org/10.36782/ijsr.v3i2.84
}

\begin{abstract}
ABSTRAK
Pesatnya perkembangan teknologi dan informasi menjadikan publik (masyarakat) menjadi sangat kritis terhadap kebijakan yang ditempuh pemerintah. Hal tersebut mengharuskan lembaga kepolisian dapat memelihara keamanan, ketertiban masyarakat, menegakkan hukum, memberikan perlindungan, pengayoman dan pelayanan kepada masyarakat. Hubungan Masyarakat (humas) merupakan instansi yang mempunyai tugas memahami dan mengevaluasi berbagai opini publik agar tercipta keharmonisan antara suatu instansi dengan publik. Guna peningkatan kualitas SDM (Sumber Daya Manusia) di kepolisian diperlukan personil yang memiliki kemampuan dalam menyelesaikan permasalahan yang terjadi di masyarakat. Dalam menyelesaikan permasalahan tersebut di perlukan kerjasama antara kepolisian, perguruan tinggi dan masyarakat. Kontribusi perguruan tinggi kepada kepolisian dan masyarakat dengan melakukan kegiatan pengabdian kepada masyarakat bekerjasama dengan Polresta Tangerang. Metode yang di gunakan dalam pengabdian masyarakat adalah dengan memberikan pelatihan peranan humas anggota Polresta Tangerang melalui zoom cloud meeting. Pelatihan Peranan Humas bertujuan untuk memberikan pengetahuan kehumasan meliputi kesamaan dalam komunikasi, fungsi humas, prinsip-prinsip dasar kehumasan, fungsi manajemen masyarakat dan manajemen hubungan media supaya menjadi polisi yang berkualitas. Hasil evaluasi kegiatan pelatihan disimpulkan bahwa pelatihan yang dilakukan mampu meningkatkan pemahaman peserta mengenai peranan humas.
\end{abstract}

Kata kunci: Humas, Polisi, Sumber Daya Manusia.

\section{ABSTRACT}

The rapid technology development and information made public (community) being so critical to the policies was taken by the government. This requires police institution to maintain of security guards, public order, enforce the law, provides protection, aegis and service to the community. Public Relations (PR) is an agency which have a duty to understand and evaluate a variety of public opinion in order to help to create harmony between particular agencies with the public. In order to increase quality of human resources in Police Department are required personnel with the ability in resolving problems the happens in society. In resolving these problems, that needed cooperation between police department, college and the community. The contribution of college to police department and the community with conducting the devotion to the community in cooperation Polresta Tangerang. The method in use in devotion community is by providing training of the role of public relations to Polresta Tangerang 
members through zoom cloud meeting. The role of public relations training aimed at giving public knowledge include similarity in communication, public relations function, basic principles of public relations, the management of the community and management of media relations may be good quality police. The evaluation of the training be concluded that the training that performed capable of increase understanding participants on the role of public relations.

Keywords: Human Resources, Police, Public Relations.

\section{PENDAHULUAN}

Manajemen hubungan masyarakat (humas) merupakan komunikasi dua arah antara organisasi dengan publik (masyarakat) secara timbal balik dalam rangka mendukung fungsi dan tujuan manajemen dalam meningkatkan pembinaan kerjasama serta pemenuhan kepentingan bersama (Rosady, 2005).

Humas merupakan salah satu bagian dari suatu instansi yang mempunyai tugas memahami dan mengevaluasi berbagai opini publik atau isu publik terhadap suatu instansi yang digunakan sebagai masukan terhadap berbagai kebijakan agar tercipta keharmonisan antara suatu instansi dengan publik sebagai tujuan akhir. Humas sebagai komunikator publik harus mampu menyampaikan segala informasi kepada masyarakat dengan baik (Saleh, 2018).

Humas dalam lembaga pemerintah mempunyai tugas menyebarkan informasi, kebijakan, program dan kegiatan-kegiatan pemerintah kepada masyarakat. Humas adalah pihak yang akan membangun dan mempertahankan hubungan baik antara organisasi dengan publik sebagai pihak yang berpengaruh untuk kelangsungan organisasi tersebut (Cutlip dkk., 2011).

Dapat disimpulkan humas adalah merupakan instansi yang mempunyai tugas memahami dan mengevaluasi berbagai opini publik dengan komunikasi dua arah antara organisasi dengan publik (masyarakat) agar tercipta keharmonisan antara suatu instansi dengan publik sebagai tujuan akhir.

Kepolisian merupakan organisasi pemerintah yang salah satu fungsinya adalah sebagai pelindung dan pelayan masyarakat Indonesia. Kepolisian merupakan lembaga pemerintah yang menjaga nama baik organisasi, negara, kepolisian perlu menjalin hubungan dengan masyarakat. Tertuang dalam UndangUndang Nomor 2 Tahun 2002 Pasal 2 tentang tugas kepolisian memelihara keamanan dan ketertiban masyarakat, menegakkan hukum dan memberikan perlindungan, pengayoman dan pelayanan kepada masyarakat (Undang-Undang Republik Indonesia Nomor 2 Tahun 2002).

Kepolisian tidak bisa menjalankan tugasnya sendiri, kepolisian perlu bekerjasama serta membutuhkan dukungan dari berbagai pihak. Tugas kepolisian yang selalu bersinggungan 
langsung dengan masyarakat, dituntut untuk lebih cepat tanggap dalam hal pelayanan dan pelaporan untuk itulah diperlukan kepolisian yang berkualitas. Berbagai upaya dilakukan oleh lembaga kepolisian dalam meningkatkan kualitas polisi dalam bidang pelayanan (Setyowati, 2020).

Polisi dituntut untuk lebih dekat dengan masyarakat agar dapat terciptanya hubungan yang sinergis dan harmonis antara polisi dan masyarakat. Polisi dan masyarakat dapat bekerjasama dalam pemberantasan berbagai pelanggaran hukum atau tindakan kriminal yang marak terjadi guna terciptanya kondisi negara Indonesia yang aman.

Untuk memperbaiki citra institusi Polisi di mata masyarakat, harus mampu mendapatkan simpati masyarakat lewat capaian sejumlah prestasi dan menjalin kemitraan dengan masyarakat. Citra adalah sebagai kesan seseorang atau individu tentang suatu yang muncul sebagai hasil dari pengetahuan dan pengalamannya (Ardianto \& Sumirat, 2004).

Sedangkan menurut David A. Raker dalam Nova (2011), citra didefinisikan sebagai seperangkat anggapan, impresi atau gambaran seseorang atau sekelompok orang mengenai objek bersangkutan. Berdasarkan kondisi tersebut, dalam peningkatan kualitas SDM kepolisian dipandang perlu diadakannya kegiatan pelatihan peran humas di kepolisian bekerjasama dengan Polresta Tangerang.
Polresta Tangerang adalah instansi kepolisian di daerah Banten yang berada dibawah pimpinan Polres Kota Tangerang. Polres adalah struktur komando Republik Indonesia di daerah kabupaten/kota. Peserta yang mengikuti kegiatan pelatihan peran humas yang termasuk dalam wilayah 19 kecamatan di kota Tangerang meliputi Curug, Sepatan, Sepatan Timur, Teluknaga, Kosambi, Pakuhaji, Legok, Kelapa Dua, Pagedangan dan Cisauk (Polresmetrotangerangkota.com)

\section{METODE KEGIATAN}

Metode yang digunakan dalam kegiatan pengabdian masyarakat ini adalah dengan memberikan pelatihan peranan humas kepada anggota Polresta Tangerang melalui zoom cloud meeting mengingat adanya pandemi Covid-19 pemerintah melarang kegiatan langsung atau tatap muka. Aplikasi ini memudahkan pengguna untuk bertatap muka secara virtual menggunakan video, suara ataupun keduanya (Idcloudhost.com, 2020).

Adapun tahapan kegiatan pengabdian masyarakat ini adalah tahap persiapan, pelaksanaan program dan evaluasi (Arsi dkk., 2019).

Dalam tahap persiapan kegiatan yang dilakukan adalah:

1. Melakukan diskusi mengenai tujuan kegiatan Pengabdian kepada Masayarakat (PkM) Dosen Universitas Esa Unggul yang di sambut sangat baik oleh Humas Polresta Tangerang. 
Disepakati tema pelatihan adalah peningkatan kualitas SDM anggota Polresta Tangerang.

2. Melakukan Kunjungan kerjasama dengan Polresta Tangerang dalam rangka mengatur jadwal kegiatan pelatihan.

3. Memperoleh data-data yang diperlukan dalam pelaksanaan kegiatan

Tahapan ini dilakukan guna mempersiapkan acara pelatihan tersebut sebelum sampai pada tahap pelaksanaan.

Tahap Pelaksanaan adalah tahap kegiatan atau realiasasi kegiatan yaitu dengan memberikan pelatihan peranan Humas kepada anggota Polresta Tangerang. Adapun materi yang di berikan pada saat pelaksanaan, yaitu:

1. Pentingnya Kesamaan dalam Komunikasi

2. Perkembangan Fungsi Kehumasan

3. Prinsip-Prinsip Dasar Kehumasan

4. Proses Kehumasan

5. Fungsi Manajemen Masyarakat

6. Manajemen Hubungan Media

Dasar dari materi yang diberikan berdasarkan teori-teori kehumasan. Menurut Cutlip dkk. (2011), peran Humas adalah seseorang yang mampu:

1. Penasehat Ahli (Expert Prescriber), seorang praktisi humas yang berpengalaman dan memiliki kemampuan tinggi dapat membantu mencarikan solusi dalam penyelesaian masalah hubungan dengan publiknya.
2. Fasilitator Komunikasi

(Communication Facilitator), dalam hal ini praktisi humas bertindak sebagai komunikator atau mediator untuk membantu pihak manajemen dalam hal mendengar apa yang diinginnkan dan diharapkan oleh publiknya

3. Fasilitator Pemecah Masalah (Problem Solving Facilitator), peranan praktisi humas dalam pemecahan masalah persoalan humas ini merupakan bagian dari tim manajemen. Hal ini dimaksudkan untuk membantu pimpinan organisasi baik sebagai penasihat (adviser) hingga pemimpin organisasi mampu mengambil tindakan dan mengeksekusi (keputusan) dalam mengatasi persoalan atau krisis yang tengah dihadapi, secara rasional dan profesional.

4. Teknisi Komunikasi (Communications technician), peranan communications technician ini menjadikan praktisi humas sebagai journalist in recident yang hanya menyediakan layanan teknis komunikasi atau dikenal dengan of communication in organization.

Kegiatan pelatihan ini dilakukan dengan melibatkan tiga orang dosen dari Fakultas IImu Komunikasi Universitas Esa Unggul. Tim pengabdian dipilih berdasarkan bidang keahlian yang dimiliki sehingga dapat menunjang kegiatan Pengabdian kepada Masyarakat (PkM), Peserta pelatihan adalah seluruh anggota Polresta Tangerang, kegiatan dilakukan melalui zoom cloud meeting. Pelaksanaan kegiatan 
pelatihan Pengabdian kepada Masyarakat (PkM) pada hari Senin tanggal 15 s.d. 17 Februari 2021 pukul 08.30 - 14.30 WIB.

Tahap Evaluasi kegiatan dilakukan dengan melihat hasil pelatihan oleh penerima manfaat kegiatan. Berdasarkan hasil pengamatan yang dilakukan peserta pelatihan dapat memahami dan mengaplikasikan cakupan tugas dan perananya sebagai fungsi humas di kepolisian. Rangkaian kegiatan pelatihan ini di akhiri dengan melakukan diskusi mengenai manfaat pelatihan yang didapatkan anggota Polresta Tangerang

"Kegiatan pelatihan ini sangat memberikan manfaat karena kesibukan di lapangan membuat kami kurang mendapatkan informasi terbaru mengenai bagaimana melakukan pendekatan kepada masyarakat dalam menangani permasalahan yang terjadi, dengan adanya kegiatan pelatihan ini memberikan nafas baru dalam menjalankan tugas" kutipan Bapak Cecep dari Legok.

\section{HASIL DAN PEMBAHASAN}

Hasil yang dicapai dalam pelatihan peranan humas dalam meningkatkan kualitas SDM pada anggota Polresta Tangerang berdasarkan diskusi dengan peserta pelatihan dan pengamatan langsung melalui zoom cloud meeting selama pelatihan berlangsung memberikan hasil sebagai berikut :

1. Semakin pahamnya anggota Polresta

Tangerang dalam memahami pentingnya komunikasi dua arah antara anggota Polresta Tangerang dengan masyarakat agar tercipta kehamonisan dalam mencapai tujuan akhir.
2. Meningkatnya pemahaman anggota Polresta Tangerang mengenai fungsi manajemen humas dalam mengevaluasi opini, sikap dan perilaku masyarakat

3. Meningkatnya pemahaman anggota Polresta Tangerang mengenai bagaimana meningkatkan citra dan reputasi yang baik di masyarakat.

4. Meningkatnya pemahaman peserta pelatihan dalam menjalin hubungan yang baik dengan media dalam rangka penyampaian informasi membentuk citra positif kepolisian.

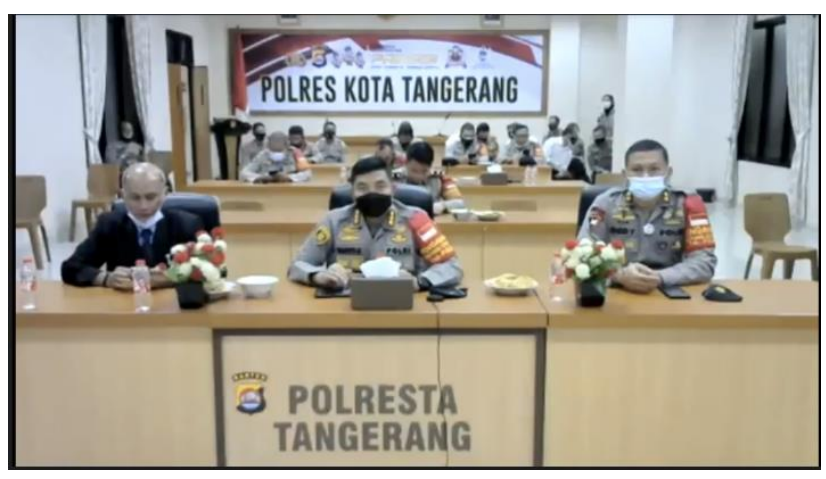

Gambar 1. Pelatihan Dihadiri oleh Kapolres Tangerang

Kegiatan pengabdian kepada masyarakat ini adalah sebagai tanggung jawab sosial dosen sebagai salah satu dari Tridarma Perguruan Tinggi yang ditujukan agar dapat memberikan pemahaman peranan humas anggota Polresta Tangerang. Kegiatan pelatihan peranan humas diikuti oleh perwakilan anggota Polresta meliputi wilayah Curug, Sepatan, Sepatan Timur, Teluknaga, Kosambi, Pakuhaji, Legok, Kelapa Dua, Pagedangan, dan Cisauk. 


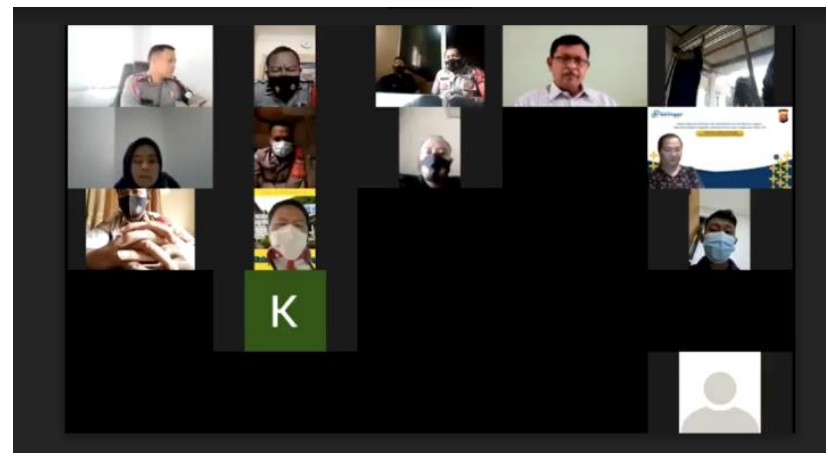

Gambar 2. Kegiatan Pelatihan Dilakukan Secara Virtual

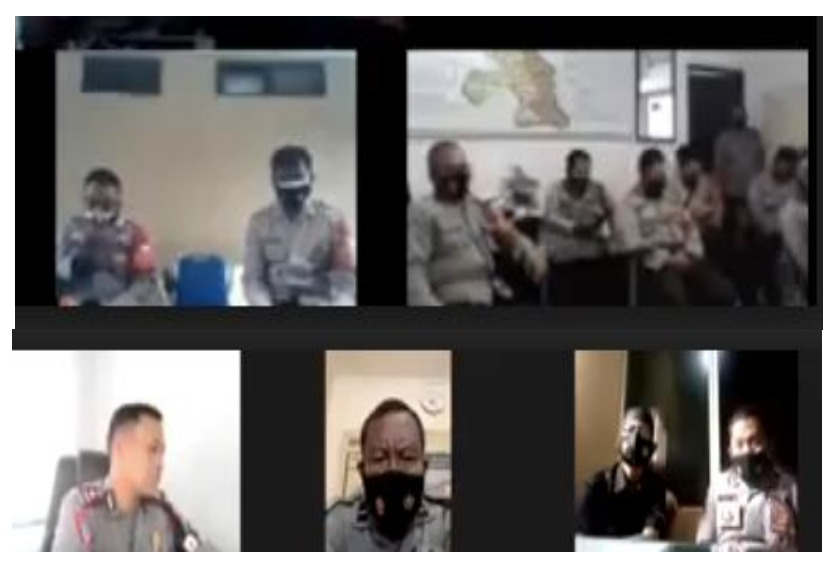

Gambar 3. Peserta Kegiatan Pelatihan

\section{KESIMPULAN}

Dapat disimpulkan bahwa, melalui pelatihan ini diharapkan mampu meningkatkan pengetahuan dan pemahaman peranan Humas anggota Polresta Tangerang, sehingga dapat bersama-sama masyarakat meningkatkan ketertiban dan keamanan Negara Republik Indonesia yang kita cintai. Bidang pekerjaan Humas pastinya tidak terlepas dari prinsip komunikasi, yaitu menciptakan suatu komunikasi yang efektif. Melalui pelatihan aggota Polresta Tangerang dapat menempatkan tugas dan fungsinya didalam organisasi dan masyarakat.
Perguruan tinggi melalui Pelaksanaan Pengabdian kepada masyarakat merupakan kewajiban yang harus dilakukan secara berkesinambungan, oleh sebab itu kerjasama antara kepolisian, Perguruan Tinggi, dan masyarakat untuk mampu mengatasi permasalahan yang dihadapi dan memberikan solusi bersama, dengan harapan terciptanya hubungan yang sinergis dan harmonis antara polisi dan masyarakat. Dari hasil kegiatan yang telah dilaksanakan dapat disimpulkan bahwa:

1. Peserta mampu memahami komunikasi yang efektif

2. Peserta memahami cakupan tugas dan peran sebagai fungsi humas di kepolisian.

3. Peserta memahami pentingnya hubungan baaik dengan media dan dalam rangka membentuk citra yang positif bagi Kepolisian.

4. Peserta memahami pentingnya menjalin hubungan baik dengan khalayak atau masyarakat membentuk citra posistif.

Melihat hasil kegiatan peserta sangat antusias, untuk kegiatan berikutnya dengan harapan dapat dilakukan pelatihan lainnya, sehingga pengetahuan anggota Polresta semakin luas dan berkembang.

Saran guna perbaikan kegiatan berikutnya pelatihan dapat dilakukan secara tatap muka dan menambah peserta pelatihan agar ilmu yang sampaikan dapat memberikan manfaat dalam penerapan peranan humas di masyarakat. 


\section{DAFTAR PUSTAKA}

Ardianto, E., Sumirat, S. (2004). Dasar-Dasar Public Relations, Cetakan Ketiga. Bandung: Remaja Rosdakarya.

Arsi, P., Waningsih, S., Pambudi, A. S. \& Maisa, W. (2019). Peningkatan Kualitas SDM Dengan Pemanfaatan Iptek melalui Pelatihan Komputer Dasar dan Internet pada Anggota Polsek Kedungbanteng. Jurnal Abdimas BSI: Jurnal Pengabdian Kepada Masyarakat, 2(2), 191-196.

Cutlip, S. M., Center, A. H., \& Broom, G. M. (2011). Effective Public Relations Edisi Kesembilan. Cetakan ke-4. Jakarta: Prenada Media Group.

Idcloudhost.com. (2020). Mengenal Aplikasi Zoom: Cara Install dan Fitur- Fitur Zoom Meeting (Lengkap). Diakses dari https://idcloudhost.com/mengenal-aplikasi -zoom-cara-install-dan-fitur-fitur-zoom-me eting-lengkap/

Nova, F. (2011). Crisis Public Relations: Strategi Public Relations Menghadapi Krisis, Mengelola Isu, Membangun Citra, dan Reputasi Perusahaan. Jakarta: Rajawali Grafindo Persada.
Polresmetrotangerangkota.com.

Profil Kepolisian Resort Metro Tangerang Kota. Diakses dari https://polresmetrotangerang kota.com/

Rosady, R. (2005). Manajemen Public Relations dan Media Komunikasi. Jakarta: PT Raja Grafindo Persada.

Saleh, D. M. (2018). Peran Humas dalam Memberikan Pelayanan kepada Masyarakat di Dinas Komunikasi Informasi dan Persandian Kota Yogyakarta [Skripsi]. Fakultas Ekonomi Universitas Negeri Yogyakarta, Yogyakarta.

Setyowati, D. A. (2020). Peran Humas dalam Mensosialisasikan Pelayanan dan Penyuluhan (P2) untuk Mewujudkan Kantibmas di Polsek Seberida Kabupaten Indragiri Hulu [Skripsi]. Fakultas Dakwah dan Komunikasi Universitas Islam Negeri Sultan Syarif Kasim Riau, Riau.

Undang-Undang Republik Indonesia Nomor 2 Tahun 2002 Kepolisian Negara Republik indonesia. 8 Januari 2002. Lembaran Negara Republik Indonesia Tahun 2002 Nomor 2. Jakarta. 
Indonesian Journal for Social Responsibility (IJSR) Vol. 3, No. 02, (2021), hal. 75-82 